Corrigendum

\title{
Corrigendum to "Synchronism of Holocene East Asian monsoon variations and North Atlantic drift-ice tracers" [Quaternary Research 65 (2006) 443-449]
}

\author{
Stephen C. Porter ${ }^{\mathrm{a}, *}$, Zhou Weijian ${ }^{\mathrm{b}}$ \\ ${ }^{a}$ Department of Earth and Space Sciences, University of Washington, Seattle, WA 98195, USA \\ ${ }^{\mathrm{b}}$ Institute of Earth Environment, Chinese Academy of Sciences, 10 Fenghui South Road, Xi'an High-Tech Zone, Xi'an 710054, People's Republic of China
}

Received 10 November 2005

Available online 1 February 2007

On page 445, in Figure 3, all columns indicating the ages followed by the standard deviation values are shown incorrectly using minuses instead of plus/minus symbols. For the reader's convenience, the corrected Figure 3 is shown on the following page along with its legend.

DOI of original article: 10.1016/j.yqres.2006.01.007.

* Corresponding author.

E-mail address: scporter@u.washington.edu (S.C. Porter). 


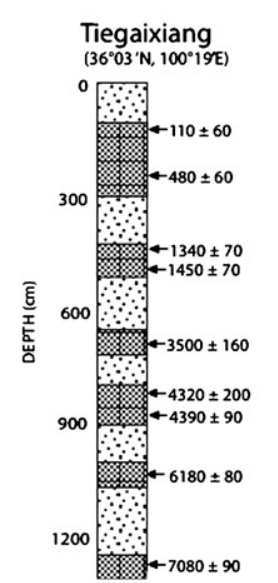

(10)

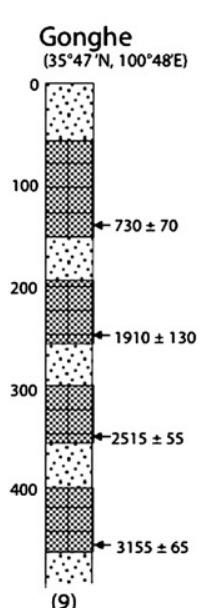

(9)
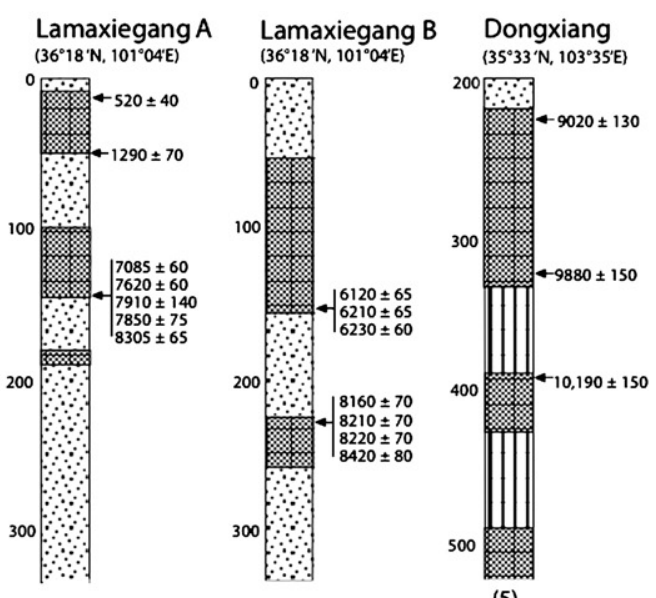

(5)

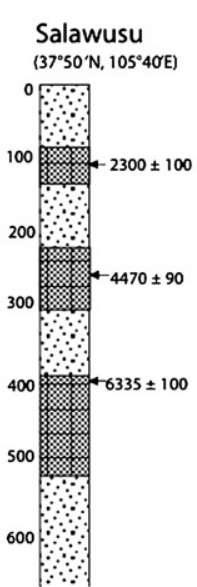

(1)

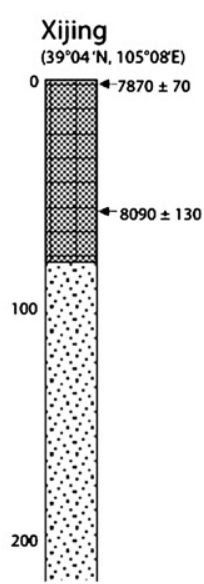

(8)

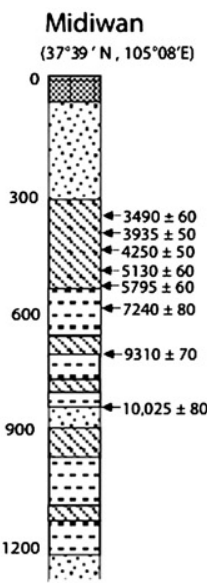

$(2-6,8)$
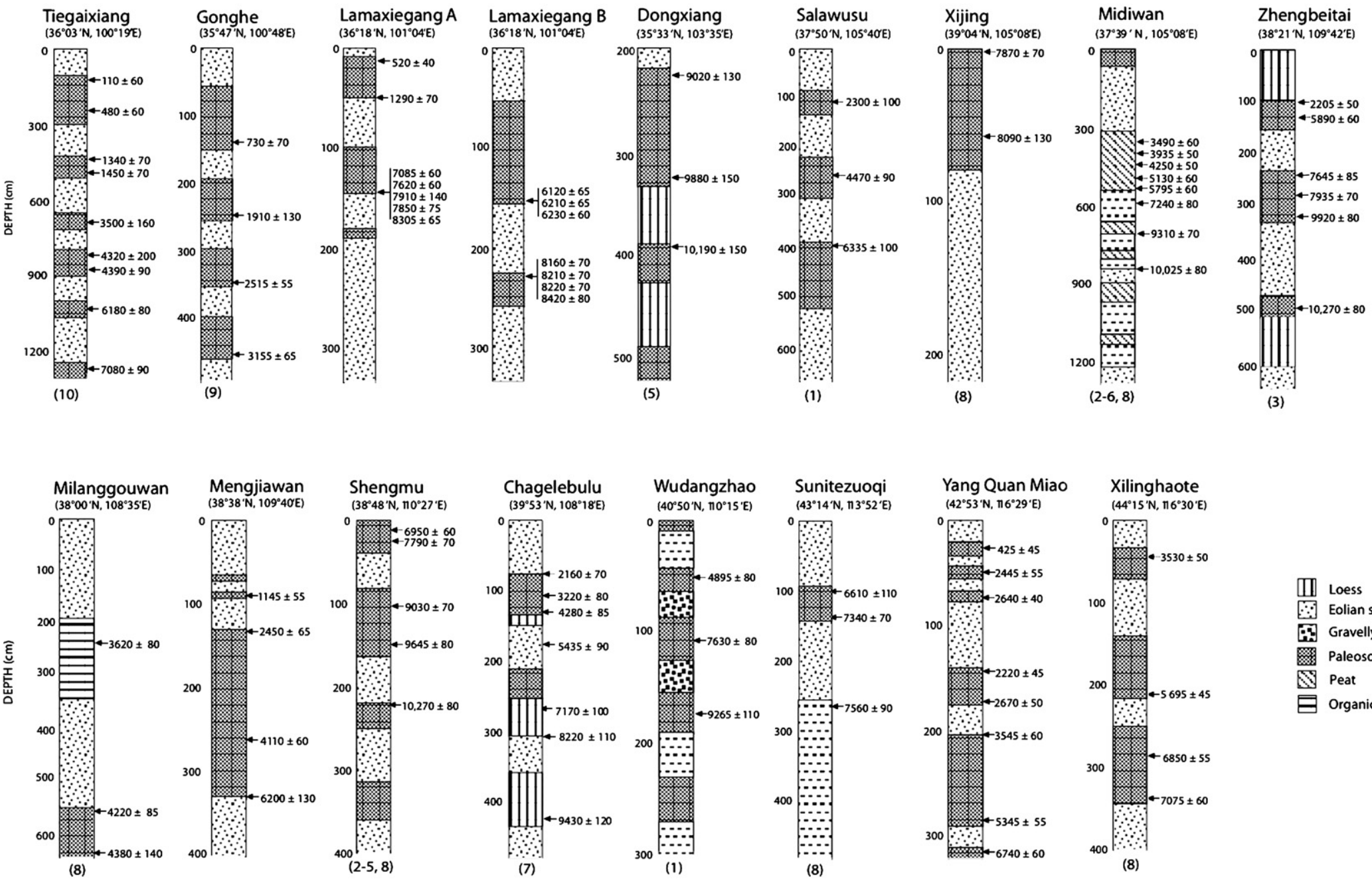

(3)

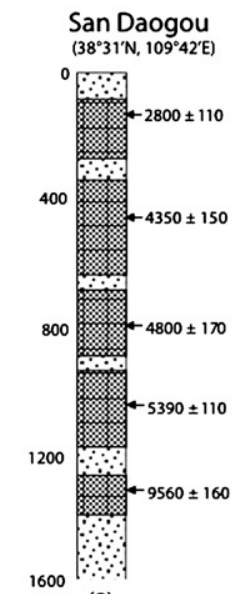

(9)

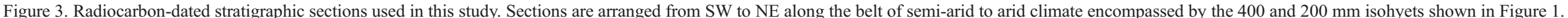

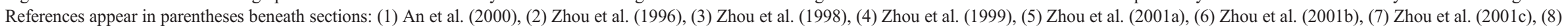
Zhou et al. (2002) (9) Dong et al. (1996), (10) Gao et al. (1993). Sections lacking references are reported here for the first time. 